Erratum

\title{
Erratum to "Impact Analysis of Carbon Tax on the Renewal Planning of Energy Supply System for an Office Building” [Energy 35 (2010) 1040-1046]
}

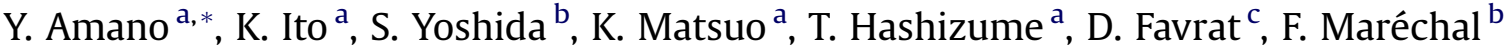 \\ ${ }^{a}$ Research Institute for Science and Engineering, Waseda University, 17, Kikui-cho, Shinjuku-ku, Tokyo 162-0044, Japan \\ ${ }^{\mathrm{b}}$ Energy Use Research and Development Center, Kansai Electric Power Co., Inc., 3-11-20 Nakoji, Amagasaki, Hyogo 661-0974, Japan \\ ${ }^{\mathrm{c}}$ Industrial Energy Systems Laboratory, École Polytechnique Fédérale de Lausanne (EPFL), Station 9, CH1015 Lausanne, Switzerland
}

Available online 19 September 2010

Author F. Maréchal ${ }^{\mathrm{b}}$ should be listed as F. Maréchal ${ }^{\mathrm{c}}$. Please note the correction of the affiliation.

DOI of original article: 10.1016/j.energy.2009.06.023.

* Corresponding author. Tel.: +81 33203 4437; fax: +81332033231.

E-mail address: yoshiha@waseda.jp (Y. Amano). 